\title{
REDUCING THE LENGHT OF WORKING HOURS AS A MEANS OF REDUCING YOUTH UNEMPLOYMENT
}

\author{
D. Stoyanova* \\ Department of Economics, Faculty of Economic and Social Sciences, Plovdiv University \\ "Paisii Hilendarski", Plovdiv, Bulgaria
}

\begin{abstract}
One of the most significant problems on the labor market in Bulgaria and in the EU is considered - the youth unemployment. The main objective of this article is to present the characteristics measurement of youth unemployment, and that youth unemployment is a consequence of increasing or maintaining the length of working hours in a prevailing growth of the labor productivity. At the European level on an analysis and evaluation are subjected the existing employment schemes of short-time working. On this basis were assessed real possibilities to limit the high youth unemployment.
\end{abstract}

Key words: youth unemployment, labor market, length of working hours

\section{INTRODUCTION}

Youth unemployment is a serious social problem, which is associated with non-use of resources in the national economy and an inability significant part of the younger generation to socialize through participation in economic life and consumption. Significant amounts of unemployment in some EU countries make it the subject of extensive research and analysis. Following the global and national change outlines the structural deficiencies in the form of insufficient capacity and willingness to adapt, and the disparity between supply and demand in the labor market. Because that is necessary to examine the causes of youth unemployment. They can be of different nature, but most modern youth unemployment is a consequence of increasing or maintaining the length of working time in terms of the prevailing labor productivity growth, as well as the disparity between the needs of labor markets and professional qualification characteristics of the youth labor resources.

\section{METHODOLOGY}

Youth unemployment is a major problem affecting the political and economic

\footnotetext{
*Correspondence to: PhD student Dobrinka Stoyanova, Department of Economics, Faculty of economic and social sciences, Plovdiv University "Paisii Hilendarski", 24, Tsar Assen Str., 4000 Plovdiv, Bulgaria,e-mail:bini_stoyanova@abv.bg
}

development of many countries in the EU. Unemployed youth have limited opportunity to participate effectively to national development and therefore need youth unemployment to undergo thorough analysis and based on this analysis to track the effectiveness of existing policies. For analysis purposes should first clarify what is the content of the term "youth", then choose the indicators that measure youth unemployment. It must be noted that this study is based on data of the ILO, Eurostat, NSI and EA. on data ILO EUROSTAT, NSI and EA.

\section{RESULTS}

There is no generally accepted definition of "youth" as a national and international level. Different countries and organizations deal with different definitions, which are formed on the basis of the criterion "age" .For the purposes of statistics at the United Nations (UN) defines "youth" as a person aged between 15 and 24 years. With the assumption that in different Member States may have a different interpretation of that concept. This definition was first given by the UN Secretary General in 1981. in his report to the General Assembly by Resolution № A / 36/215, paragraph 8 of the Annex. Later with General Assembly resolution № A / RES / 56/117 of 2001., The Resolution of the Commission for Social Development №E/2007/26 \& E / CN.5 / $2007 / 8$ of 2007 and General Assembly 
resolution № A / RES / 62/126 of $2008 \mathrm{~m}$ the same definition of "youth" .Some of organs and UN sub-organizations have different definitions of "youth" Youth Fund -According as young people are those aged between 15 and 32 years and according to the African Youth Charter, between 15 and 35 years. United Nations Educational, Scientific and even the culture UNESCO uses different definitions of "youth" depending on the context, but mostly for young people accept all who are aged, in which the transition from training to find first job. For purposes of analysis, however, it is essential that interpretation of the term "youth" of the International Labour Organisation (ILO). It applies the methodology of the UN Secretariat, which, as already mentioned above, defines youth as people aged 15 to 24 years and persons over 25 years old to apply. For the majority of the analyzes, the EU and in particular the Statistical Office of the European Commission, Eurostat, the term "young people" means all persons who are aged between 15 and 24 years (inclusive). In the EU issues on the protection of young people in the workplace are affected by Directive 94/33 / EC of 22.06.1994. Bulgaria as an EU member must reconcile their standards and apply the same methodology. In this regard, the National Statistical Institute (NSI) uses the same definition of young people as Evrostat. On the other hand Employment Agency (NEA), which is committed to the promotion of employment by the Minister of Labour and Social Policy and fulfilling its statistical activities based Law on Employment Promotion, distinguishes two groups among young people. Besides standard applied group aged 15 to 24 years, young people are also accepted and persons from 15 to 29 years. In chapter six, section three of the Act on Promotion of Employment is regulated youth employment.

The age group that is accepted by the EA as young people was adopted by the Ministry of Youth and Sports. Within the meaning of $\S 1$ of the Additional Provisions of the youth, renovated in SG br.31, effective 20.04.12g. "Youths" are persons aged between 15 and 29 years inclusive. In addressing youth unemployment in Bulgaria it is important to take into account discrepancies in interpretation of "youth" by NSI and I to come to a coherent analysis of the rate of youth unemployment.

Before the analysis of youth unemployment is necessary to clarify what are the indicators to measure this phenomenon and what their contents. To this end, this article will examine the tools used MOT. This organization has developed a tool for analysis and study of the labor market, called "Basic indicators of the labor market" (Key Indicators of the Labour Market-KILM) .First KILM were established in 1999. and are 18 and serve for the assessment of the labor market worldwide. Most importantly, our work indicates 10 Youth unemployment (KILM 10. Youth unemployment). As in the preparation of KILM use data from these international sources, which in turn are supplied with information from national sources: Department of Statistics ILO (LABORSTA and ILOSTAT), Statistical Institute UNESKO, World Bank, Statistical Office of the EU, Eurostat, the Organisation for Economic Cooperation and Development (OECD) and the Statistical Bureau for the analysis of the labor market of the United States.

International standards for unemployment and in particular youth and adopted by Resolution of the 13th International Conference on Statistics in Geneva in 1982 According to this resolution be adopted for unemployed persons over a certain age (which depends on the laws of individual countries) which meet the following conditions: 1 . during the period they have not worked for a fee ie they are without work; 2 . They are available to start work at any time; 3. actively seeking work, which may include registration at labor offices directly offering workforce and others.

In the analysis of the level and dynamics of youth unemployment it is necessary to clarify who is also the indicator for measuring this phenomenon and what is its content.

According to the ILO, there are three key indicators to summarize the situation of young people in the labor market:

- The rate of youth unemployment (Youth unemployment rate), which is calculated as the percentage of unemployed young people in the youth labor force (employed and unemployed young people).

From the analysis of data for youth unemployment in the EU for the period 20112013. (Table 1) it becomes clear that the share of young people who are unemployed increased from $21.4 \%$ for 2011 . of $23.4 \%$ for 2013. ie by 2 percentage points. Such rate of youth unemployment means that more than one in five young people seeking employment in Europe can not find a job. Between individual Member States there are significant differences, data for 2013 show that the youth unemployment rate ranges from $7.9 \%$ in Germany and $9.2 \%$ in Austria (the EU 
countries with the lowest youth unemployment) to $55.5 \%$ in Spain and $58.3 \%$ in Greece (Member States with the highest youth unemployment). Recent data show a worrying trend that indicates that every second young person is unemployed. The rate of youth unemployment in Bulgaria for 2013. 28.4\%. This shows that in our country there are about three times more unemployed young people to countries with the lowest unemployment rate.

\begin{tabular}{|c|c|c|c|}
\hline & \multicolumn{3}{|c|}{ Youth unemployment rate } \\
\hline & 2011 & 2012 & 2013 \\
\hline EU-28 & 21.5 & 23.0 & 23.5 \\
\hline Euro area (EA-18) & 20.9 & 23.1 & 24.0 \\
\hline Belgium & 18.7 & 19.8 & 23.7 \\
\hline Bulgaria & 25.0 & 28.1 & 28.4 \\
\hline Czech Republic & 18.1 & 19.5 & 18.9 \\
\hline Denmark & 14.2 & 14.1 & 13.0 \\
\hline Germany & 8.6 & 8.1 & 7.9 \\
\hline Estonia $\left({ }^{2}\right)$ & 22.4 & 20.9 & 18.7 \\
\hline Ireland & 29.1 & 30.4 & 26.8 \\
\hline Greece & 44.7 & 55.3 & 58.3 \\
\hline Spain & 46.2 & 52.9 & 55.5 \\
\hline France $\left({ }^{2}\right)$ & 22.6 & 24.4 & 24.8 \\
\hline Croatia & 36.1 & 43.0 & 50.0 \\
\hline Italy & 29.1 & 35.3 & 40.0 \\
\hline Cyprus & 22.4 & 27.7 & 38.9 \\
\hline Latvia & 31.0 & 28.5 & 23.2 \\
\hline Lithuania & 32.6 & 26.7 & 21.9 \\
\hline Luxembourg & 16.4 & 18.0 & 16.9 \\
\hline Hungary & 26.1 & 28.1 & 27.2 \\
\hline Malta & 13.3 & 14.1 & 13.0 \\
\hline Netherlands & 7.6 & 9.5 & 11.0 \\
\hline Austria $\left({ }^{2}\right)$ & 8.3 & 8.7 & 9.2 \\
\hline Poland & 25.8 & 26.5 & 27.3 \\
\hline Portugal & 30.3 & 37.9 & 38.1 \\
\hline Romania & 23.7 & 22.7 & 23.6 \\
\hline Slovenia & 15.7 & 20.6 & 21.6 \\
\hline Slovakia & 33.7 & 34.0 & 33.7 \\
\hline Finland & 20.1 & 19.0 & 19.9 \\
\hline Sweden & 22.8 & 23.7 & 23.6 \\
\hline United Kingdom & 21.1 & 21.0 & 20.5 \\
\hline
\end{tabular}

Table 1. Youth unemployment rate, 2011-2013

Source: Eurostat

Measurement of youth unemployment with Youth unemployment rate, however, requires a number of difficulties and they relate that most people in this age group are outside the labor market, as many young people are trained and therefore unable to work. This requires calculating youth unemployment and other indicators.

- Another measure of youth unemployment is the factor that shows the share of the unemployed youths of the total population between 15 and 24 years (Youth unemployment ratio) -not only active but inactive, such as students.

From the analysis of Table 2 shows that in 2011. Youth unemployment ratio in the EU is $9.1 \%$, which means that 57.5 million people aged between 15 and 24 years 5.2 million. Young people are unemployed. For comparison -during 2013 this indicator grew $9.8 \%$, which shows that the number of unemployed youth increased $5.6 \mathrm{mln}$. The youth unemployment ratio rule is always less than the youth unemployment rate The reason for this is due to the different denominators when calculating these indicators.

- The third indicator survey of the population aged 15-24 years is the factor that shows the number of young people not engaged in employment, education or training (NEET). This is a measure of the untapped potential of young people. NEET group includes young unemployed and economically inactive young people. 


\begin{tabular}{|c|c|c|c|}
\hline & \multicolumn{3}{|c|}{ Youth unemployment ratio } \\
\hline & 2011 & 2012 & 2013 \\
\hline EU-28 & 9.1 & 9.7 & 9.8 \\
\hline Euro area (EA-18) & 8.7 & 9.5 & 9.8 \\
\hline Belgium & 6.0 & 6.2 & 7.3 \\
\hline Bulgaria & 7.4 & 8.5 & 8.4 \\
\hline Czech Republic & 5.4 & 6.1 & 6.0 \\
\hline Denmark & 9.6 & 9.1 & 8.1 \\
\hline Germany & 4.5 & 4.1 & 4.0 \\
\hline Estonia $\left({ }^{2}\right)$ & 9.1 & 8.7 & 7.4 \\
\hline Ireland & 12.1 & 12.3 & 10.6 \\
\hline Greece & 13.0 & 16.1 & 16.6 \\
\hline Spain & 19.0 & 20.6 & 20.8 \\
\hline France $\left({ }^{2}\right)$ & 8.4 & 8.9 & 9.0 \\
\hline Croatia & 11.3 & 12.7 & 14.4 \\
\hline Italy & 8.0 & 10.1 & 10.9 \\
\hline Cyprus & 8.7 & 10.8 & 15.0 \\
\hline Latvia & 11.6 & 11.5 & 9.1 \\
\hline Lithuania & 9.2 & 7.8 & 6.9 \\
\hline Luxembourg & 4.2 & 5.0 & 4.0 \\
\hline Hungary & 6.4 & 7.3 & 7.4 \\
\hline Malta & 7.1 & 7.2 & 7.0 \\
\hline Netherlands & 5.3 & 6.6 & 7.7 \\
\hline Austria $\left({ }^{2}\right)$ & 5.0 & 5.2 & 5.4 \\
\hline Poland & 8.6 & 8.9 & 9.1 \\
\hline Portugal & 11.7 & 14.3 & 13.5 \\
\hline Romania & 7.4 & 7.0 & 7.3 \\
\hline Slovenia & 5.9 & 7.1 & 7.3 \\
\hline Slovakia & 10.1 & 10.4 & 10.4 \\
\hline Finland & 10.1 & 9.8 & 10.3 \\
\hline Sweden & 12.1 & 12.4 & 12.8 \\
\hline United Kingdom & 12.4 & 12.4 & 12.0 \\
\hline
\end{tabular}

Table 2. Youth unemployment ratio, 2011-2013

Source:Eurostat

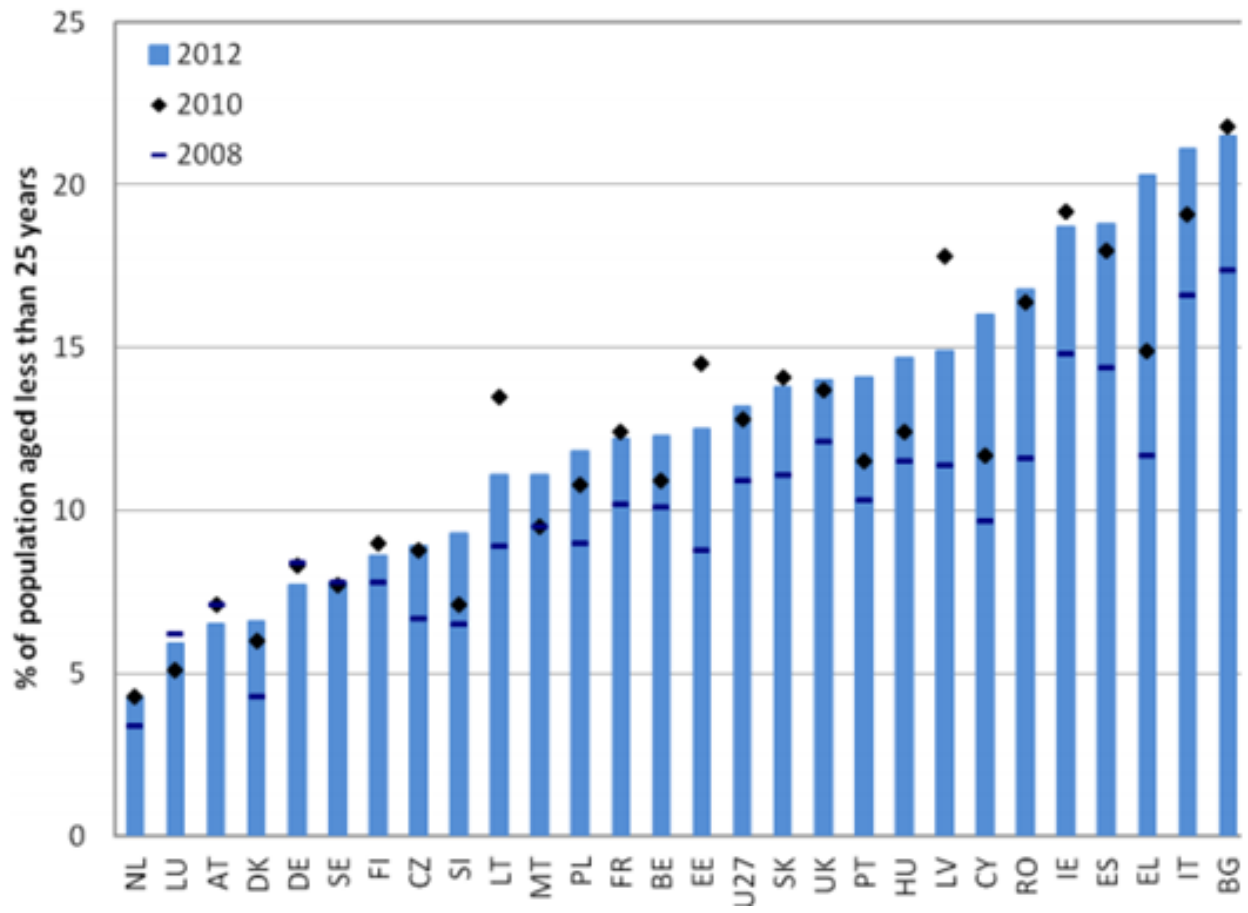

Figure 1. Young people not in employment,education or training (NEET) for EU Member States, 2008,2010 and 2012

Source:Eurostat 
From the analysis of the data in Figure 1 for 2012. it is clear that Bulgaria is a Member State in the EU with the highest share of the group of NEET-about $22 \%$, while in the Netherlands the figure is more than five times lower value-about 4\% for 2012 (Figure 1). Overall, in 2012 about 7.5 million young people are neither in employment, nor educated, nor in training. This represents a serious problem for the efficient use and development of human capital. To overcome this problem it is necessary to take a number of measures such as increasing the employment rate among young people by improving education, training and skills.

Length of work and youth unemployment Youth unemployment depends on many factors, among the most important is the length of working time. Several European countries use this tool as the primary means to reduce youth unemployment.

Employment of short-time working is a measure that is the basis for dealing with the negative effects of the crisis on the labor market and especially on young people. It is therefore necessary to examine the link between youth unemployment and hours of work and the performance of the schemes for employment of short-time working.

On the one hand, work part-time can contribute to job creation in the medium or long term would have as a result of contracts full time. Reduction of working hours also leads to the need to employ more staff or to limit the cuts. This is because in fixed costs of production and labor productivity, a shorter working day leads to an increase in the need for labor, respectively, a decrease in unemployment.

On the other hand the result of the shorter working hours also restrict the flow of skilled professionals abroad, as well as providing job opportunities to students.

The main objective of these schemes reduced working hours is to limit unemployment and protect salaries by full or partial compensation of employees by providing government subsidies for salaries paid directly to employees or the company itself. In some countries that apply this measure subsidies are supplemented by payments from employers.

By working time flexibility companies manage to retain their human capital, so that when the economy recovers be able to recover the initial production levels and avoid the procedures for hiring new staff. At the same time they guarantee the social security rights of employees and enable them to maintain their purchasing power.

A serious problem in the implementation of short-time work as a means of reducing youth unemployment has led state policy and limited budgets that need more revenue to finance such anti-crisis measures.

\section{CONCLUSION}

Youth unemployment is a problem and it is necessary to assess both the content of this phenomenon and indicators to measure it. The main objective is to increase activity in this age group, as this is an important prerequisite for stable economic progress. Serious potential to limit youth unemployment is reducing working hours etc or employment schemes of shorttime working. The application of these schemes is desirable, as they relate to reducing youth unemployment and growth in production, which leads to improving the living standards of young people.

\section{REFERENCES}

1. Alter, Hannah (2006): Moeglichkeiten der Erfassung von Arbeitszeit in Unternehmensbefragungen. In: Statistisches Bundesamt "Wirtschaft und Statistik" 7/2006.759-767.

2. Boeckler-

Institut,www.boeckler.de/pdf/p_ta_element e_Arbeitszeitverkuerzung_2009.pdf

3. Lehndorf, Steffen, Arbeitszeitpolitik nach der Kurzarbeit, (Script 2010)

4. Wanger, Susanne (2010): Die Altersteilzeit im Zusammenspiel individueller und betrieblicher Einflussfaktoren. In: WSIMitteilungen Jg. 63, H.8. S. 395-403.

5. Wolf, Elke (1999): Arbeitszeiten im Wandel. Welche Rolle spielt die Veränderung der Wirtschaftsstruktur? Mannheim.

6. www.ilo.org 